\title{
The Information Superhighway: the Atom-bomb of the 90's
}

\author{
Nadia Repenning \\ Department of Sociology and College of Music \\ University of Colorado, Boulder CO 80309-0327 \\ repennin@ucsub.colorado.edu
}

Fax: (303) 581-9118

\section{Introduction}

Technology is driving society by making, but rarely keeping, promises concerning benefits to political ideologies and life styles. The Nuclear Age, starting in the 50 's, gave us the atom bomb and proclaimed it to be the ultimate mechanism to protect the Western society from the Communist ideology. Space Age, reaching its climax in 1969 with the first lunar landing, promised new technological breakthroughs that would improve the quality of life. In retrospect, the benefits to society are controversial at best, once we take into account health risks and the astronomic cost caused by developing, using and cleaning up the artifacts of the nuclear and the Space Age. Finally, in the 90's we embrace the "clean" Information Age with its noble promises to increase equity, improve education, and boost economical competitiveness.

This paper discusses possible implications that can arise from ubiquitous information technologies such as the Information Superhighway. One risk is the further polarization of societies into "haves" and "have nots" due to the ability, or lack thereof, to access and then to effectively use information technology. The race for the more powerful nuclear bomb and the race to the moon have been replaced with the race of enabling people through information technology to process increasingly more information in less and less time. Ultimately, this could lead to an information technology rearmament analogous to the one in the cold war. Instead of trying to outnumber our enemies in terms of nuclear bombs we acquire improved information technology allowing us to deal with information more efficiently than our competitors. That is, we need to be able to read more e-mails, process more faxes, and navigate faster through hyper media spaces just to remain competitive. This paper discusses some of the consequences of information technology rearmament such as the technological polarization, the emergence of ubiquitous forms of labor, and the use of technology as instruments of competition.

\section{Technology drives Society}

The thesis of this paper is that the Information Age shares many important properties with the Nuclear Age and the Space Age. All three ages describe instances in which society was or still is profoundly changed through technology. Technology, at its ever increasing pace, is no longer just serving society, but instead it is driving it.

To analyze the impact of technology on society we distinguish between benefits, costs and side effects:

- Benefits. The three eras are linked to breakthrough technologies that have produced complex technological artifacts serving as instruments of competition. Competition can be at different levels including entire nations, industries and individuals.

The Nuclear Age is responsible for the atom and the hydrogen bomb. These artifacts were used in the Cold War era to keep a strategic balance between the USA and Russia. The perceived benefits from this technology included the preservation of political ideologies.

In the Space Age, winning the race to the moon seemed crucial from a propaganda perspective. Kennedy believed that the struggle against international Communism would be fought and decided in the underdeveloped nations of the world (Clarfield \& Wiecek, 1984). The moon landing served as benchmark to prove to the world the technological superiority of the USA.

- Costs. Development of technology is extremely costly. Depending on the level of competition for which the 
technology is used, governments need to persuade or force tax payers to finance technology development, or industry needs to persuade customers to buy into technology.

In the Nuclear Age fear of communism (McCarthyism) in society proved to be an ideal vehicle to justify massive financial investments in the research of more powerful nuclear technology (Cayton, 1993).

The race of the superpowers became palpable the moment that President John F. Kennedy declared the moon landing as a national goal. The idea of space domination was used to justify tremendous spending efforts.

- Side Effects. The complexity of technology may prevent the complete understanding of its impact on society. The perception of technology as an instrument of competition can lead to a technological rearmament situation. Like the development of the nuclear weapons in the Cold War era, this rearmament, ultimately serving nobody, may escalate into enormous cost.

Today we are dealing with the left-overs of the Cold War. Nuclear wastes and "Space garbage" are increasing. Institutions and society are struggling to find a safe way to dispose of nuclear debris. Concerns about security increase since nuclear and space material in the wrong hands could prove to be an inconceivable peril.

The next section elaborates on benefits, costs and side effects of the Information Age and relates them to the Nuclear Age and Space Age.

\section{Information Age: Technological Rearmament}

At first glance the Information Age seems to have little in common with the Nuclear Age and the Space Age, yet, it shares the same origins. Information Age promises to improve the quality of life by empowering individuals. The Information Age hopes to enable more people in more places to have access to more information. The ultimate artifact of the Information Age, the computer, can help people in their daily life. Potentially, it can increase equity by providing information access to remote communities. It can become a powerful learning tool.
The Information Age is following the footsteps of the Nuclear Age and the Space Age as it is already starting to escalate in a technological rearmament. The market is being flooded with more technology and more information.

Information technology is an instrument of competition that is shifting from a national level to an individual level. ARPA, starting one of the biggest networking development efforts, anticipated the use of networking as a mean to create a more resilient nuclear defense system against Russia (Rheingold, 1993). Even before the end of the Cold War, the true potential of the network as an information medium between people instead of between autonomous computers was realized (Maddox, 1994). The use of e-mail, MUDs, news groups and the World Wide Web (WWW), to name just a few inter-person electronic information services, are expanding at an exponential rate of 15 million subscribers as of 1994 with a projected doubling of subscribers in 1995 (Gomery, 1994). Telecommunication companies realize the enormous markets to sell new information services. The ability of individuals to deal with the ever increasing information glut (Roszak, 1994) becomes a predominant skill in the Information Age society. Essential technology, as an instrument of competition, is no longer at the level of nations but instead is used by individuals and sold by private companies.

Commercialization of information technology will set a new bias to the benefit, cost and side effect outcomes. As in the case of the Nuclear Age and Space Age we are dealing with a complex technology whose impact on society is hard to predict. Again we should think in terms of perceived benefit, cost and side effects. The fact that the big information technology players are private companies that are trying to sell devices and services to individuals makes it seem more than likely that these companies will try to bias our perspective of benefit, cost and side effects in order to make a profit. Barlow (Barlow, 1995) suggests that the only consumer architecture that is more manipulative than the information superhighway visions of cable and communication companies is the Las Vegas Strip.

One day we may look back and, as in the case of the nuclear and the Space Age, realize the absurdness of this new technological rearmament. Did the technological rearmament really benefit society or did we get lured into a giant marketing fad? The stakes are high. We are not just 
promised a nicer looking pair of shoes. Information technology is supposed to extend our minds and to improve the very fabric of society. Let us take a glimpse at the future in the form of a vision fostered by private industry to assess the benefits, costs and side effects of information technology.

\subsection{YOU WILL: Sending a Fax from the Beach}

A variety of communication companies such as phone companies paint rosy visionary pictures of a new and improved Information Age Society. One company exposes us to a series of scenarios featuring happy, technologically empowered people.

For instance, we see a man laying in a lounge chair on a beautiful beach somewhere in the Pacific holding some sort of futuristic communication device in his hands. He has some business to do (Figure 1). All smiles and satisfied, he signs the message that he just wrote and sends it away. The scene concludes with an explicit "You Will" message.

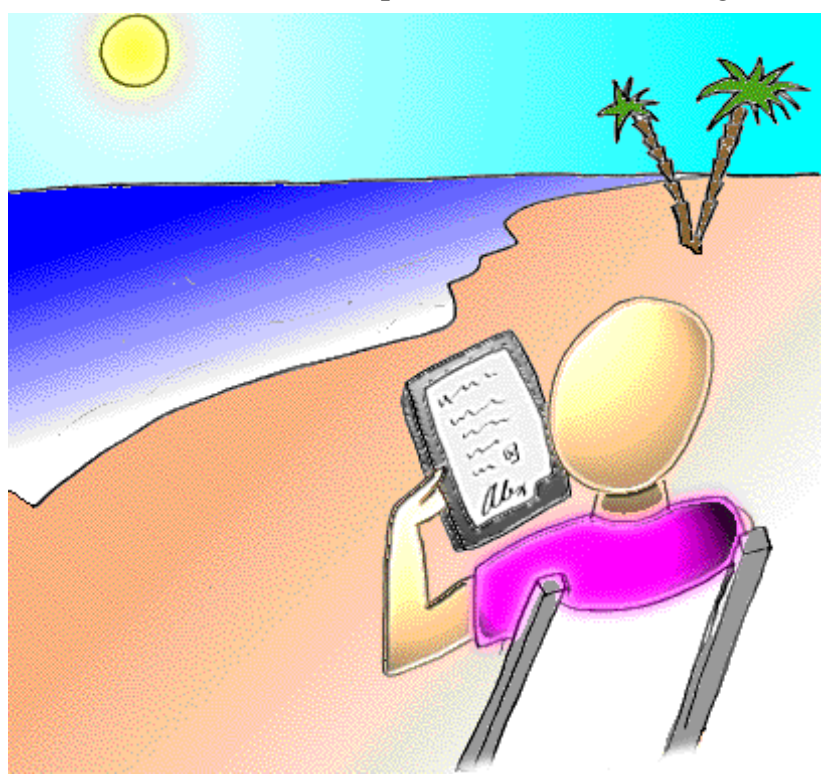

Figure 1. Sending Fax from the Beach

Who is going to benefit from technology at what cost? When and where can this technology be used at what consequence? Why should we buy into this kind of technology? These questions are elaborated in the following sections.

\subsection{Who: Technological Polarization}

New complex technologies can polarize society into people who can use it and into people who can not. The majority of visions put forward feature young, successful, highly educated people. For instance, the man sending a fax from the beach can obviously afford a pleasing vacation. Will future information technology be universally affordable and usable by society? Will it be like phones today, in that most people can buy phones and know how to operate them, or will there be an intrinsic threshold of complexity of this technology preventing its general use?

While the Nuclear Age and the Space Age affected society as a whole they brought nations together as a unity. The nuclear bomb did not create classes because its function was not selective. The Information Age is prone to create social classes since it will affect the individual more directly than key technology of the two previous ages. Ratan points out that access to information technology generally breaks down along traditional class lines (Ratan, 1995). The bulk of computers in American households is found in wealthy and upper-middle class families. These are typically the families who already have a good education. Low income families, who may benefit from information technology the most, can typically not afford to make technology investments. Even if information technology becomes more affordable, it tends to have a polarizing effect on society. The ability to buy technology is necessary but not sufficient. Education has to become a key issue to be able to make effective use of technology. These informational skills, in turn, are needed to find a job (Toffler, 1990).

Working conditions may change considerably. Already we are facing, especially in white collar jobs, a shift in working behavior. The boundaries between work at the office and work at home are starting to blur.

\subsection{When and Where: Ubiquitous Form of Labor}

To push the notion of time and place of work to its extreme may result in a new ubiquitous form of labor in which work and leisure are no longer clearly separated activities. While this new form of labor may be attractive on the one hand, we should not forget that, on the other hand, the desire to be able to work at any time any place is fueled by companies who live off selling devices and services to us.

At first glance this new ubiquitous form of labor seems very positive. For instance, in the virtual office, employees are given portable, networked computing devices that can be used any place any time (Nadeau, 1995). Employees only need to come in to the physical office for face-to-face 
meetings. Office spaces are no longer rigidly allocated to individuals. One big benefit of this approach is to decrease costs by reducing office space. To be sure, this approach to empower people represents a technological challenge. To build devices that allow communication with other human beings from any place and at any time are by no means trivial. However, the cost to society should not be reduced to budget items such as office rent. How humane is the ubiquitous form of labor?

If we can be reached at any time and any place, how will this fragment our lives? Do we really want to be able to send faxes or read e-mail on our vacation? How desirable is this new ubiquity of labor really? Miniaturized, mobile machinery serving as tool no longer requires us to be at work. Work is with us. To abandon a clear work leisure distinction may make it difficult to recognize when it is time to stop working. If we are not careful, we may migrate from a work-to-life to a life-to-work society.

\subsection{Why: Instruments of Competition}

Information technology, like nuclear and space technology has turned into an instrument of competition empowering some individuals more than others to deal with information effectively. The early perception of computers as tools to free society from repetitive, or even boring tasks in order to allow society to focus on creative activities never quite materialized. Neither have computers brought us a democratic renaissance (Roszak, 1994). The 8 hour work day never got reduced to 5 hours. Quite the opposite is the case. The perceived obligation to create and absorb more and more information driven by the need to compete in a capitalist society has led to an increase of work hours. We must ask ourselves where this technological rearmament will lead and if, like in the Nuclear and Space Age, it could escalate again into a situation of extreme cost with little or no gain.

Unlike in the Nuclear and Space Age, competition is no longer between nations, but it is now between individuals. We are made to believe that mastering these new tools will give us a leading edge. The question is no longer who has more nuclear power or can send a space ship to the moon earlier. What counts now is that we as a society, and as individuals, can digest an ever increasing amount of information. If your competitor has acquired tool $\mathrm{X}$ to deal with more e-mails or to send more faxes, then you must catch up or, better yet, buy tool Y that promises even better performance.

\subsection{Dealing with the Future}

As consumers of the Information Age technology we need to become more cautious with what lies in the future. We need to recognize the power we have in directing our future. As in the Nuclear and Space Age, the issues are complex. But even so, it will be most important to at least speculate on how the future of the Information Age should look and what kind of impact it will have on our lives.

\section{Conclusions}

Technology has changed our world view. The Nuclear, Space and Information Ages have and still have profound implications for society. Our vision of power and control changed with Nuclear weapons. The Space Age made us realize how small our world is; ultimately we saw a new vision of ourselves and had to re-think our role in the universe. The Information Age is introducing us to a new form of labor.

Technology has always played an important role in society. Yet, in the more recent history of mankind, starting with the Nuclear Age, the pace of technological development has reached a critical threshold preventing us from understanding the implications of technology to society. History can serve our understanding of the process that societies go through when they are driven by technology. We can reflect on the Nuclear and the Space Age. However, we also must understand the differences of the Information Age from the Nuclear and Space Ages. In contrast to the Nuclear and Space Ages, the Information Age entails technology empowering individuals. This technology is sold by private companies, directly to us, the customers. Consequential, the motives driving the Information Age are more commercial in nature. Technology is not necessarily developed to improve the overall quality of life, but to make a profit.

\section{Acknowledgments}

My best thanks to my husband Alexander Repenning for his support and the many discussions that led to this paper. 


\section{References}

Barlow, J. P. (1995). Death from Above. Communications of the ACM, $\underline{38}(5), 17-20$.

Cayton, M. K. (1993). Encyclopedia of American Social History. New York: Charles Scribner's Sons.

Clarfield, G. H., \& Wiecek, W. M. (1984). Nuclear America (1st ed.). New York: Harper \& Row.

Gomery, D. (1994). In Search of the Cybermarket. Wired(Summer), 9-17.

Maddox, T. (1994). The Cultural Consequences of The Information Superhighway. Wired(Summer), 29-39.

Nadeau, M. (1995). Not Lost in Space. Byte, 20(6), 50-54.

Ratan, S. (1995). A New Divide Between Haves and HaveNots? Time, 145(12), 25-26.

Rheingold, H. (1993). The Virtual Community: Homesteading on the Electronic Frontier (1st ed.). Reading, Mass.: Addison-Wesley Publishing Company.

Roszak, T. (1994). The Cult of Information (2nd ed.). Berkeley: University of California Press.

Toffler, A. (1990). Powershift: Knowledge, Wealth, and Violence at the Edge of the 21st Century (1st ed.). New York: Bantam Books. 